\title{
Samantha Adams Festschrift: The Dot at the End of the Funnel-TILT Remembers Samantha Adams
}

\author{
Robin L. Pierce ${ }^{1}$ Anna Berti Suman ${ }^{1}$ Bert-Jaap Koops ${ }^{1}$ Ronald Leenes ${ }^{1}$ \\ 1 Tilburg Institute for Law, Technology, and Society, Tilburg, \\ The Netherlands \\ Appl Clin Inform 2018;9:490-492.
}

\section{Introduction: The Foundation}

When colleagues at The Tilburg Institute for Law, Technology, and Society (TILT) learned of Samantha Adam's death, the shock and sadness unfolded on multiple levels. Sam, as she was known by everyone, had been at TILT for 4 years and, in that time, had become a beloved colleague and friend to many, as well as the leading force and driver for the development of a dedicated health research line at TILT. Sam was in the process of bringing the many strands of her work together from a research and teaching career that explored issues in health through the lens of Science Technology and Society studies (STS), Health Policy, and Medical Informatics.

Sam had decided that eHealth would be the umbrella under which she would integrate her research and teaching. Consequently, when she came to TILT, her longstanding interest in medical informatics and online health research readily and naturally transformed into the launch of a rapidly developing research line on eHealth. ${ }^{1}$ But as Sam was always quick to point out, "eHealth is not 'one thing'!" "You really cannot talk about the regulation of eHealth or the ethics of eHealth - it involves a vast array of different technologies giving rise to different issues." Although we shared this understanding, it was clear that this had become one of Sam's rallying cries, a pet peeve. But at the root of this annoyance was the fact that, as Sam pointed out, not getting your foundational terms right at the outset will significantly lower the depth, quality, and value of the analysis that could be done as a result. It was this kind of insistence on intellectual integrity that guided Sam's work. Some may have experienced it as stubbornness, but the result was indisputable-Sam's research foundations were solid.

\section{Methods and Teaching}

Perhaps it was this appreciation for the importance of solid foundations that also contributed to Sam's enthusiastic

embrace of methods. Her mastery of qualitative methods was not just a basis for much of her research and publications, but she also came to be known for her ability to teach qualitative methods, often across disciplines. Sam loved teaching methods and had envisioned developing a methods curriculum at Tilburg University. She shared her knowledge of methods with colleagues, always ready for a conversation, crash course, or Masterclass, whatever was called for. Former PhD students often expressed appreciation for her in-depth mastery and ability to train in methods.

In what turned out to be her last months at TILT, Sam dedicated her enthusiasm and methodological skills to set up a course for the PhDs students of the Tilburg Law School (TLS). Very soon, it was clear that Sam could bring an invaluable contribution to the improvement of the methodology curriculum of numerous, primarily legal, $\mathrm{PhD}$ researchers. This challenging task did not intimidate Sam, who was eagerly ready to start a debate on methodology in a legal environment. The PhD community at TLS will deeply miss her expertise and pedagogical skills.

Sam also innovated teaching at the Master level. Under the eHealth umbrella, she designed the Health, Care, Technology, and Regulation course for TILT's Law \& Technology Master students. We witnessed Sam's commitment to make the course successful, her ability to engage with, and motivate the students. The shape Sam gave to the course greatly reflects her multifaceted expertise and her endless curiosity. With the wisdom acquired through many years of researching multiple strands of eHealth, she invited the students to reflect and challenge assumptions about eHealth. Sam also supervised students writing theses on the course's topics. To guide the students toward the "right" research questions, Sam used to draw a funnel and ask the students what they aimed at understanding, metaphorically placing a dot at the end of the funnel. Sam applied the same capacity to guide PhD students toward a targeted questioning in their thesis. She often asked her PhD supervisees: "what is the case of

(C) 2018 Georg Thieme Verlag KG Stuttgart · New York
DOI https://doi.org/ 10.1055/s-0038-1641596. ISSN 1869-0327.
Address for correspondence Robin L. Pierce, JD, PhD, Tilburg Institute for Law, Technology, and Society, Tilburg 5000LE, The Netherlands (e-mail: r.l.pierce@tilburguniversity. edu). 
your case?" And, tirelessly, Sam was able to show all the unimaginable nuances that an apparently simple question could hide.

\section{Beyond the Clinic}

When Sam took up STS as a research tool, she quickly saw the links between Foucault and her longstanding topic of interest-medical informatics and online health research. The clinic, she observed, had moved out of a single building and into the streets, cars, and homes by way of the various forms of eHealth. Thus, the observation that took place in the clinic, now also took place in many other locales. Weaving notions of surveillance into her analysis of the transformations of the clinic, Sam challenged the simple assumption that more knowledge about one's health is better, questioning what it means to have access to so much knowledge about one's health and asking how various mHealth technologies, like wearables, can affect society on both a societal and individual level. This also brought her work into the realm of ethics, where she asked questions about implications of these technologies ${ }^{2}$ for personal responsibility, for example.

While many of us spend most of our careers sitting behind our university desks, Sam was one of those rare scholars who are able to really successfully combine both theory and practice. She made a point of working in multiple settings, ranging from hospitals, general practitioner (GP) offices, clinics, social media sites, and various online environments. ${ }^{3}$ Sam sought to link the real world with the academic world, and was also sought out for precisely this ability. Most recently she had taken on a project with colleagues at TILT to explore ethical and societal aspects of a sewage surveillance system aimed at detecting synthetic drug production through wastewater analysis, adding yet another dimension to her surveillance studies perspective.

In another surprising strand of her research at TILT, Sam teamed up with TILT's cybersecurity researchers to investigate the governance of cybersecurity. ${ }^{4}$ For a report commissioned by the Dutch Ministry of Security and Justice to map the cybersecurity landscape in Canada, Estonia, Germany, the Netherlands, and the United Kingdom, ${ }^{5}$ she drew upon one of those hidden founts of expertise she turned out to possess. Few people who followed and used her research in health and technology will realize that the first major in her Bachelor's studies at Duke University consisted of political science, with a specialization in international security. (She received the Alona E. Evans Prize for Outstanding Scholarship in International Law for her thesis in political science in 1998.) Drawing from her existing knowledge of international security, and effortlessly updating it with recent literature, Sam contributed a lucid text on the concept of governance and the distinctions between government, regulation, and governance. Having ensured that the foundational terms of cybersecurity and governance were right at the outset, Sam then brought together all the findings of the multicountry multicase-study (botnet mitigation, vital infrastructure protection, and identity infrastructure protection) to draw conclusions on the distribution of responsibilities in the highly polycentric landscape of cybersecurity governance.

Sam was not only aware of power imbalances in governance in her research. She was also very attentive to gender issues within the institutional setting of the university, reflecting her Bachelor's second major: women's studies. She often engaged in conversations on the struggles of women to achieve high academic positions and the persisting imbalance between male and female professors. Furthermore, Sam gave attention to the work-private life equilibrium, especially for the PhDs she supervised. She was able to bring the conversation from the professional to the personal level to investigate whether anything was going wrong in the latter sphere. In the workplace, Sam was attentive to the shyer people, often inviting colleagues to share a lunch in her office or in the university's cafes to develop more intimate talks.

As colleagues of Sam, we enjoyed conversations with her on the widest range of topics, from the intricacies of nanotechnology as a method of surveillance and the pros and cons of bioconstitutionalism as an analytic framework, to critiques of research methodology and constructive ideas on teaching methods. She could engage with just about any topic. And she rarely lacked an opinion. When Sam became a colleague at TILT, many of us learned of her passion for reading and that she was a consummate history buff. When asked, she readily offered recommendations for readingand (perhaps even more usefully) for not reading. As a way of continuing this legacy, among the ways that Sam's colleagues have chosen to honor her and her work, Sam's books will find a home in the newly established Samantha Adams Health Library at Tilburg University, housed at her departmental home of TILT.

\section{The Dot and the Funnel}

Sam Adams passed away in the midst of her career, just when she was pulling together all the many strands that formed the fabric of her almost two decades' worth of research and teaching experience. It is tempting to wonder which dot she would have placed at the end of the funnel, if she had been forced to answer her own question: but what is the case of your case? What insight do you hope to achieve? We can envision, perhaps, the start of an answer that sketches a grand vision of health beyond the clinic and how technology challenges not only our understanding of medicine and health in contemporary society, but even of our understanding of this understanding. But while we are listening to this imaginary answer, we hear her interrupt herself at some point, to explain that this dot is, of course, not "one thing," but a complex of things, questions, assumptions, and issues, and that it is a useless endeavor to try and simplify it into a single grand scheme of things. Throughout Sam's time at TILT, her work continued to branch out as much as it converged, weaving her contribution to the body of knowledge into an ever more intricate, multicolored, puzzling yet appealing pattern. 
If there is anything that Sam has taught us, it is this. Nothing is as simple as it seems or as we would like it to be, but we can always arrive at a better understanding of whatever it is we want to know if we simply start from the basics: solid concepts, explicit assumptions, theoretical grounding, and rigorous method. The dot is there, certainly, but it is not there at the end of the funnel. Rather, it is at the beginning, and when we reverse our perspective, we can see the real role that the dot at the small end of the funnel has to play. It is the starting point of academic research and teaching, from which anything can branch out. Sam's starting point was intellectual integrity, which she poured into the small end of the funnel to see it branch out into ever broader and better understandings of health and technology, and of any other odd issue she could not resist adding into the mix. What comes out at the broad end of the funnel is not a finished dot, but an extremely rich flow of wide-ranging contributions that we-in academia, in policy, and in practice-can take up and bring forward.

\section{References}

1 Adams SA, Van Veghel D, Dekker L. Developing a research agenda on ethical issues related to using social media in healthcare. Camb Q Healthc Ethics 2015;24(03):293-302

2 Adams SA, Petersen C. Precision medicine: opportunities, possibilities, and challenges for patients and providers. J Am Med Inform Assoc 2016;23(04):787-790

3 Adams SA, Paul KT, Ketelaars C, Robben P. The use of mystery guests by the Dutch Health Inspectorate: results of a pilot study in long-term intramural elderly care. Health Policy 2015;119(06): 821-830

4 Adams SA, Silva K, Koops BJ, Van der Sloot B. The regulation of botnets: how does cybersecurity governance theory work when everyone is a stakeholder? In: Ellis R, Mohan V, eds. Wired: Cybersecurity Governance. London, UK: Wiley; 2018

5 Adams SA, Brokx M, Dalla Corte L, et al. The Governance of Cybersecurity. A comparative quick scan of approaches in Canada, Estonia, Germany, the Netherlands and the UK. Tilburg/The Hague: TILT/WODC; 2015. Available at: https://www.wodc.nl/binaries/ 2484-volledige-tekst_tcm28-73672.pdf. Accessed March 29, 2018 